\title{
Determination of nugget size in resistance projection welding: numerical method with experimental measurements
}

\author{
Danial Mohammad Rezaei ${ }^{1}$, Behzad Heidarshenas ${ }^{2}$, Fazel Baniasadi ${ }^{3 *}$ \\ ${ }^{1}$ Department of Mechanical Engineering, University of Tehran, Tehran, Iran. \\ ${ }^{2}$ Mechanical Engineering Department, Faculty of Engineering, Girne American University, Girne, N. Cyprus \\ $3^{3 *}$ Corresponding Author: Department of Materials Science and Engineering, Virginia Tech, Blacksburg, VA, \\ USA, 24060, Email: Fbasadi@ vt.edu
}

\begin{abstract}
The aim of this paper is to at first evaluate the influence of three key parameters including weld current, weld time and electrode force on nugget diameter and tensile strength in resistance projection welding. Then, a 2-D axis-symmetric finite element model is developed to simulate the projection welding and predict the nugget diameter. Finally, the FEM results are compared to experimental data to verify the simulation model and simulated results. In the finite element model, the temperature-dependent material properties were taken into account.
\end{abstract}

Keywords: Resistance projection welding; Nugget size; Maximum failure load; Welding parameter.

\section{Introduction}

Resistance welding process is the most significant joining process in the automobile industry due to its high speed and suitability for automation; moreover, this process can utilize robots with electro-hydraulic or electro-mechanical actuators with high controllability and accuracy and thus, any new development of this welding process is closely influenced by the demand of this industry. Welding process, in many situations, is composed of heating, melting, solidification, and cooling but different heat source may be used such as arcs, lasers, torches, pins in friction stir welding or electron beam [1-8]. Electrical resistance spot welding process for joining two materials at their interface is a complicated interaction of electrical, thermal, mechanical, metallurgical and surface phenomena. In this process, electrodes press against two or more steel sheet and a high current is passed through the sheet-electrode system. 
Because of the electrical contact resistance, heat will be generated at electrode/work piece interfaces and faying surface [9-11]. The heat at the faying surface melts the work pieces to form a nugget. To prevent melting at the electrode/work piece interface and increase the electrode life, water is circulated in the cooling chamber of the electrode. The current carrying zone in the sheet is determined by the region over which electrodes touch the sheet and this, in turn, depends on the electrode force and consequent plastic flow at the sheetelectrode interface. The complete phenomenon is thus, an electro-thermal problem which is also influenced by plastic flow in the sheet. Coupled with this are various types of nonlinearities present in the system. For example, thermal conductivity and bulk electrical resistivity vary with the temperature. Besides, the interface resistance along sheet-sheet interface and sheet-electrode interface varies with various parameters in a very uncertain manner. Hence, a finite element code for simulating the resistance welding process which includes all those features mentioned above is developed in the present work for modeling resistance projection welding process. Over the past 20 years, research has been made enabling the use of advanced analytical procedures to more accurately simulate the welding process. However simple mathematical solutions cannot direct to the practical manufacturing processes because of the complexity of the physical processes involved in welding [12]. Furthermore, it is also impossible for any experimental technique to acquire a complete mapping of the heat distribution in a general welded structure. Computational simulation thus plays an indispensable role in the integrity analysis of such welded structures [13-17].

The first computer codes for solving one-dimensional finite difference method [18], and a two-dimensional geometry[19, 20] were used. Due to an incomplete understanding of the electrical resistance of the contact surfaces - that determines the amount of heat created several experiments were conducted to measure the resistance and ways to measure the resistance [21]. The numerical models for the analysis of the results were then used. The development of theoretical and experimental models to predict resistance between sheets was a step forward in the numerical analysis [22-25]. In 1984, Nied [26], had reported a twodimensional simulation model for analyzing resistance spot welding process of uncoated steel using commercial FEM package ANSYS. A coupled thermo-electrical with a thermomechanical analysis have been tried. Gould et.al [18], reported a one-dimensional numerical model to calculate weld nugget development during spot welding of uncoated steel. However, the model being one-dimensional, failed to account for the radial heat loss into the surrounding sheet. Cho et.al [27], had reported a two-dimensional, finite difference method based heat transfer model for the resistance spot welding process. It has been concluded from 
the publications cited above that the resistance spot weldability of aluminum alloys is not yet fully explored although there is now tremendous demand of these materials to be used in the automobile industry.

In recent years, different approaches have been introduced in simulating the process. They have used elements with the size of $0.05 \mathrm{~mm}$ and coupling time of $0.0025 \mathrm{~s}$ and each of them try to optimize some particular parameters [28-31]. For example, one of the most important parameters is the size and shape of the nugget that is affected by process parameters. For this reason, an analysis was presented that calculates the shape and size of the welding nugget and this analysis has been validated with experiments [30]. Since the physics of the process is so complicated, it is quite understandable that very little was published in the open literature on the finite element modeling which covers these many aspects.

In this paper, firstly, experiments are carried out to evaluate the influence of three key parameters including weld current, weld time and electrode force in nugget diameter and tensile strength in projection welding. Then, a 2-D axis-symmetric finite element model is developed to simulate the projection welding and predict the nugget diameter. Finally, the FEM results are compared to experimental data to verify the simulation model and simulated results. In the finite element model, the temperature-dependent material properties are taken into account. The FEM is implemented by applying the ANSYS parametric design language (APDL).

\section{Experimental procedure}

In order to investigate the influence of three key parameters including weld current, weld time and electrode force in resistance projection welding, an experimental model is fabricated as shown in Fig. 1. This model is selected according to AWS C1.4M/C1.4:2009 so that the length of each plate is $105 \mathrm{~mm}$; the width is $45 \mathrm{~mm}$; the thickness is $1 \mathrm{~mm}$. The material used in this study is low carbon steel for both plates. The projection size is also considered to be $3.5 \pm 0.1 \mathrm{~mm}$ in diameter and $1 \pm 0.1 \mathrm{~mm}$ in height. In order to make the projection on sheets, a forming mold is design and manufactured, as shown in Fig. 2. The size of the punch and die are also considered according to the standard. Other specifications are shown in Table. 1.

In order to weld the specimen with the same size and shape, a welding fixture is designed and manufactured, as shown in Fig. 3. This fixture adjusts the overlapping distance equals to $45 \mathrm{~mm}$ as well as the alignment of the projected neck with the electrode axis to make sure the electrode force is applied perpendicular to the plate. With respect to numerous standards, the 
experiment pattern is designed and considered so that electrode force, weld time and weld current are considered in two, three and five levels, respectively. The experiment is performed randomly, as shown in Table 2 .

\section{Numerical Modeling}

\subsection{Finite element Simulation}

A two-dimensional axisymmetric model is carried out through the ANSYS finite element package [32]. The finite element mesh contains two types of $2 \mathrm{D}$ elements including PLANE42, containing two degrees of freedom as Ux and Uy for mechanical analysis and PLANE67, having the capability of thermal, electrical and thermal-electrical analyses and being compatible with PLANE42. In FEM, a considerable refinement of the mesh is needed. Thus the mesh sensitivity analysis is carried out, as shown in Table 3. Comparison of temperature distributions for different mesh size is illustrated in Fig. 4. The mesh size of $2.5 \mathrm{~mm}$ is considered for further analyses and the model is shown in Fig. 5. Two types of analyses are carried out through this model; a mechanical analysis and a thermal-electric analysis. The mechanical analysis is used to analyze the compressive stresses developed during the squeeze time and the thermal-electric analysis is used to analyze the nugget growth during weld time through the temperature distribution during the period. Fig. 6 shows the schematic illustration of the computational procedure. The boundary conditions are listed in Table 4 and Table 5 and they applying condition is depicted in Fig. 7.

\subsection{Material properties}

The materials of the plates are low carbon steel $(0.1 \%$ carbon) and their thermal properties are shown in Table 6, $7[28,30]$. According to the high temperature gradient around the welding zone, the material properties change significantly. So the temperature-dependent thermal properties are used to increase the accuracy of the solution. The melting temperature of the material is defined as $1510{ }^{\circ} \mathrm{C}$ and the temperature for the phase transformation is 723 ${ }^{\circ} \mathrm{C}$. Because of the scarcity of material data at elevated temperatures and numerical problems when trying to model the actual high-temperature behavior of the material, material modeling such as considering fluid flow and phase transformation has always been a crucial issue in the welding simulation. Some simplifications and approximations are usually introduced to deal 
with this problem. Fluid flow has significant effects on the temperature distribution. However because the coupled problem between solid and liquid is not involved in FEM codes such as ANSYS and ABAQUS at present, the fluid flow and solidification of material in the weld pool cannot be considered directly. If the effect of the fluid flow is neglected, the highest temperature in the weld pool will be very high, sometimes; it is over $3000{ }^{\circ} \mathrm{C}$. This phenomenon is much different from the realistic situation. In this work, an artificially increased thermal conductivity is used to consider the fluid flow. When the temperature is higher than the melting point, in liquid range, a thermal conductivity of $110 \mathrm{~W} / \mathrm{m}^{\circ} \mathrm{C}$ is taken into account. Because the artificially increased thermal conductivity is used in the present simulation, the highest temperature of the weld pool is about $1480{ }^{\circ} \mathrm{C}$, which is much closer to the realistic situation.

Also, phase transformation has an insignificant effect on the welding simulation of low carbon steel because of a small dilation due to martensitic transformation and a relatively high transformation temperature range. Due to the numerical problems when trying to model the actual high-temperature behavior of the material and heat-affected zone (HAZ), it is assumed in this analysis that thermal properties of the weld metal and HAZ are the same as those of the base metal.

\section{Results and discussions}

\subsection{Numerical results}

A Simulation model has been developed and extensive numerical calculations were carried out to find out the nugget diameter, penetration, etc. for resistance projection welding of low carbon steel sheets using the FEM Software ANSYS. Fig. 8 shows the predicted isothermals and nugget shape.

\subsection{Experimental results}

As mentioned earlier, samples are tested through the peeling test and the tensile strength test after welding and the nugget diameter and tensile strength of the weld are recorded. It is worth noting that the test is carried out according to the standard entitled as AWS C1.4M/C1.4:2009. 


\subsubsection{Peeling test}

The peeling test is a qualitative test to determine the creation of the welding nugget. First, the samples are fixed in a clamp and then the edges of the sheet are bent. The front plate is then torn out to up to the weld nugget. Some of the samples under the peeling test are shown in Fig. 9. According to this figure, the weld nugget was formed in (a), (b), (c) and (f). However, in (d) and (e) the sheets were not merged and the weld nugget was not formed. According to the standard, AWS C1.4M/C1.4:2009, the diameter of the weld nugget for low carbon steel sheet with a thickness of $1 \mathrm{~mm}$ has to be between 3.1 and $4.4 \mathrm{~mm}$. As a result, if the nugget diameter is within the range, the welding strength will be assured. According to this table, the nugget has not been formed in many experiments and the welding has suffered from insufficient energy to melt the sheet and create the nugget.

\subsubsection{Tensile-shear test}

The tensile-shear test has been conducted on samples. According to the standard, the tensileshear strength for low carbon steel sheet with a thickness of $1 \mathrm{~mm}$ should be in the range of 2.8 to $6.5 \mathrm{KN}$. The tensile-shear results show that in many cases the tensile-shear strength is high enough, even though, the nugget has not been formed between two sheets. In order to study the effect of nugget size on tensile-shear strength, the nugget diameter and tensile-shear strength are plotted in a graph shown in Fig. 10, 11 and 12. As expected, the weld strength increased with increasing nugget diameter.

\subsubsection{Effect of parameters}

\subsubsection{Welding current}

The effect of current flow on tensile-shear strength is examined in different electrode forces. In a constant weld time and electrode force of $100 \mathrm{Kg}$, the weld strength is increased with increasing weld current, as shown in Fig. 13. This is also evident in the electrode force of 200 Kg. Increasing the welding current increases the welding energy and thus raises the temperature between the two sheets. 


\subsubsection{Welding time}

Fig. 14 shows the influence of welding time on welding strength. As shown in Fig. 14, in a constant welding current and electrode force of $100 \mathrm{Kg}$., welding strength slightly increases. However, welding strength decreases in some currents in the electrode force of $200 \mathrm{Kg}$. and thus has no specific effect. As a result, it can be stated that the effect of welding time on weld strength is not clear. In general, we can say that increasing the weld time, increases the energy between two sheets and therefore results in higher temperature. However, increasing the weld time also increases the time of applying electrode force and thus causes more liquid spraying out of the weld zone and reduces the nugget diameter.

\subsubsection{Welding Force}

The effect of electrode force on weld strength is shown in Fig. 15. The weld strength decreases with increasing electrode force in lower welding currents. However, in higher welding currents, welding strength does not change significantly with increasing force. It can be concluded that increasing electrode force increases the contact surface and thereby decreases the current density leading to less heat between two sheets and thus less welding strength.

\subsubsection{Comparison}

In order to compare the numerical simulations and experimental results, samples are cut and the cross-section of the nugget area is examined. The same is done in the numerical results and the cross-section of the nugget is compared with the experimental data. In order to determine the nugget area in numerical simulations, a specific color is considered for the parts of the metal where the temperature is above the melting point of the metal. Here, the melting point for low carbon steel is considered to be $1510^{\circ} \mathrm{C}$. Therefore, the part of the metal where the temperature is higher than $1510^{\circ} \mathrm{C}$ represents the nugget area. Fig. 16 shows the cross-section of the welding and nugget area. The cross-section of the sample No. 57 welded using $100 \mathrm{~kg}$ of electrode force, welding time of 6 cycles and a welding current of 8 kA with $5.5 \mathrm{~mm}$ of nugget diameter is shown in Fig. 17 (a). According to the welding specification for this sample, an analysis is conducted and the result is extracted, as shown in Fig. 17 (b). As stated earlier, the nugget diameter in the experiment was measured to be 5.5 $\mathrm{mm}$, while the diameter of the nugget area is $5.86 \mathrm{~mm}$ in the numerical result. This difference in nugget diameter shows approximately \%6 error in numerical results that are acceptable. Another comparison is made between the height of the welding nugget in experimental 
results and numerical data, as shown in Fig. 18. As is clear, the height of the nugget is $1.6 \mathrm{~mm}$ and 1.7 in simulation and experiment, respectively, which indicates nearly \%6 error in numerical results. Another comparison between numerical data and experimental results was made and the results brought the same \%6 error in numerical results. This comparison is made based on sample No. 45 with $100 \mathrm{~kg}$ of electrode force, welding time of 6 cycles and a welding current of $6 \mathrm{kA}$ with $3.75 \mathrm{~mm}$ of nugget diameter. Fig. 19 shows the details of the comparison.

\section{Conclusion}

In this study, three key parameters in the process of resistance projection welding process including weld current, weld time and electrode are examined by means of numerical simulation and experiments. The followings are the final conclusions:

1. Increasing the welding current increases the welding energy and thus raises the temperature between the two sheets. Therefore, the weld strength is increased with increasing weld current.

2. Increasing weld time increases the welding strength in some points and decreases the weld strength in others. Hence, it has no specific effect on weld strength. As a result, it can be stated that the effect of welding time on weld strength is not clear.

3. The same as weld time, electrode force has no clear effect on weld strength. Yet, it can be stated that in lower welding currents, weld strength decreases with increasing electrode force.

4. In this, the programming code in order to simulate and analyze the resistance projection welding was examined that the results are a good agreement with experimental data. Therefore, this code can be used for further analysis of the parameters of other resistance welding specification. 


\section{References}

1. Najdahmadi, A., A. Zarei-Hanzaki, and E. Farghadani, Mechanical properties enhancement in Ti-29Nb-13Ta-4.6 Zr alloy via heat treatment with no detrimental effect on its biocompatibility. Materials \& Design (1980-2015), 2014. 54: p. 786-791.

2. Song, Q., W. Zhang, and N. Bay, An experimental study determines the electrical contact resistance in resistance welding. Weld. J, 2005. 84(5): p. 73s-76s.

3. Han, Z., et al., Resistance spot welding: a heat transfer study. Welding journal, 1989. 68(9): p. 363s-371s.

4. Sharifi, S., et al., Leakage fault detection in Electro-Hydraulic Servo Systems using a nonlinear representation learning approach. ISA Transactions, 2018. 73: p. 154-164.

5. Sharifi, S., et al. Multi-class fault detection in electro-hydraulic servo systems using support vector machines. in Robotics and Mechatronics (ICROM), 2016 4th International Conference on. 2016. IEEE.

6. Baniasadi, F., et al., Thermal stability investigation of expanded martensite. Surface and Coatings Technology, 2016. 300: p. 87-94.

7. Azhiri, R.B., et al., Analyzing of joint strength, impact energy, and angular distortion of the $A B S$ friction stir welded joints reinforced by nanosilica addition. The International Journal of Advanced Manufacturing Technology, 2018: p. 1-14.

8. Azhiri, R.B., et al., Measurement and evaluation of joint properties in friction stir welding of ABS sheets reinforced by nanosilica addition. Measurement, 2018. 127: p. 198-204.

9. Gashteroodkhani, O.A., B. Vahidi, and A. Zaboli, Time-time matrix z-score vector-based fault analysis method for series-compensated transmission lines. Turkish Journal of Electrical Engineering \& Computer Sciences, 2017. 25: p. 2647-2659.

10. Nazari, A. and S. Farhad, Heat generation in lithium-ion batteries with different nominal capacities and chemistries. Applied Thermal Engineering, 2017. 125: p. 1501-1517.

11. Nazari, A., Heat Generation in Lithium-ion Batteries. 2016, University of Akron.

12. Gashteroodkhani, O.A. and B. Vahidi. Application of Imperialistic Competitive Algorithm to Fault Section Estimation Problem in Power Systems. in The International Conference in New Research of Elec trical Engineering and Computer Science,, Iran. 2015.

13. Nishikawa, H., H. Serizawa, and H. Murakawa, Actual application of FEM to analysis of large scale mechanical problems in welding. Science and Technology of Welding and Joining, 2007. 12(2): p. 147-152.

14. Stamenković, D. and I. Vasović, Finite element analysis of residual stress in butt welding two similar plates. Scientific technical review, 2009. 59(1): p. 57-60.

15. Rybicki, E. and R. Stonesifer, Computation of residual stresses due to multipass welds in piping systems. Journal of Pressure Vessel Technology, 1979. 101(2): p. 149-154.

16. Grignon, F., et al., Explosive welding of aluminum to aluminum: analysis, computations and experiments. International Journal of Impact Engineering, 2004. 30(10): p. 1333-1351.

17. Nickpay, M., et al. Improvement of sensitivities of concentric single-layer elements for the design of reflectarrays using split double-ring. in Electrical Engineering (ICEE), 2014 22nd Iranian Conference on. 2014. IEEE.

18. Gould, J., An examination of nugget development during spot-welding, using both experimental and analytical techniques. Welding journal, 1987. 66(1): p. S1-S10.

19. Tsai, C., et al., Modeling of resistance spot weld nugget growth. Welding Journal(USA), 1992. 71(2): p. 47.

20. Khan, J., L. Xu, and Y.-J. Chao, Prediction of nugget development during resistance spot welding using coupled thermal-electrical-mechanical model. Science and technology of welding and joining, 1999. 4(4): p. 201-207.

21. Timsit, S. Electrical contact resistance: properties of stationary interfaces. in Electrical Contacts-1998. Proceedings of the Forty-Fourth IEEE Holm Conference on Electrical Contacts (Cat. No. 98CB36238). 1998. IEEE. 
22. Babu, S., et al., Empirical model of effects of pressure and temperature on electrical contact resistance of metals. Science and Technology of Welding and Joining, 2001. 6(3): p. 126-132.

23. Vogler, M. and S. Sheppard, Electrical contact resistance under high loads and elevated temperatures. surfaces, 1993. 9(10): p. 11.

24. Khan, I., et al., Monitoring the Effect of RSW Pulsing on AHSS using FEA (SORPAS) Software. 2007, SAE Technical Paper.

25. Najdahmadi, A., J.R. Lakey, and E. Botvinick, Structural Characteristics and Diffusion Coefficient of Alginate Hydrogels Used for Cell Based Drug Delivery. MRS Advances, 2018: p. 1-10.

26. Nied, H., The finite element modeling of the resistance spot welding process. Weld. J., 1984. 63(4): p. 123.

27. Cho, H. and Y. Cho, A study of the thermal behavior in resistance spot welds. Welding Journal, 1989. 68(6): p. 236s-244s.

28. Rashid, M., et al., Influence of lubricants on electrode life in resistance spot welding of aluminum alloys. WELDING JOURNAL-NEW YORK-, 2007. 86(3): p. 62.

29. Raoelison, R., et al., Modeling and numerical simulation of the resistance spot welding of zinc coated steel sheets using rounded tip electrode: Analysis of required conditions. Applied Mathematical Modelling, 2014. 38(9-10): p. 2505-2521.

30. Eisazadeh, H., M. Hamedi, and A. Halvaee, New parametric study of nugget size in resistance spot welding process using finite element method. Materials \& Design, 2010. 31(1): p. 149157.

31. A.E. Pirbazari, P.M., B.F. Kisomi, $\mathrm{Co} / \mathrm{TiO}_{2}$ nanoparticles: preparation, characterization and its application for photocatalytic degradation of methylene blue. Desalin, Water Treat 2017. 63: p. 283-292.

32. ANSYS, C., Release 10.0 User Manual, 2006. ANSYS Inc. 


\section{Tables}

Table 1 - Invariant welding parameters.

\begin{tabular}{cc}
\hline Item & Specification \\
\hline Welding Machine & Press-type resistance welding \\
PPNT $\mathbf{1 0 0}-(\mathbf{1 0 0} \mathbf{K V A})$ \\
Electrode & $\mathbf{A} \mathbf{2}$ Class, $\mathbf{C u}-\mathbf{C r}-\mathbf{Z r}$ \\
OD: $\mathbf{2 5 m m}, \mathbf{I D}=\mathbf{1 5 m m}$ \\
Electrode Cooling System & Water-cooling \\
& Flow rate $=\mathbf{4}$ l/min \\
& Inlet Temperature $=\mathbf{2 0}{ }^{\circ} \mathrm{C}$ \\
\hline
\end{tabular}


Table 2 - Design of experiments.

\begin{tabular}{|c|c|c|c|c|c|c|c|c|c|}
\hline Sequence & $\begin{array}{c}\text { Sample } \\
\text { No. }\end{array}$ & $\begin{array}{l}\text { Electrode } \\
\text { Force }(\mathrm{Kg})\end{array}$ & $\begin{array}{l}\text { Weld Time } \\
\text { (cycle) }\end{array}$ & $\begin{array}{l}\text { Weld Current } \\
\text { (KA) }\end{array}$ & Sequence & $\begin{array}{c}\text { Sample } \\
\text { No. }\end{array}$ & $\begin{array}{l}\text { Electrode } \\
\text { Force }(\mathrm{Kg})\end{array}$ & $\begin{array}{l}\text { Weld Time } \\
\text { (cycle) }\end{array}$ & $\begin{array}{l}\text { Weld Current } \\
\text { (KA) }\end{array}$ \\
\hline $1-30$ & 30 & $100 \sim 200 \mathrm{Kg}$ & 4,5,6 cycle & $4,5,6,7,8$ KA & $30-60$ & 30 & $100 \sim 200 \mathrm{Kg}$ & 4,5,6 cycle & $4,5,6,7,8$ KA \\
\hline 1 & 28 & 200 & 4 & 8 & 31 & 59 & 200 & 5 & 8 \\
\hline 2 & 20 & 100 & 5 & 7 & 32 & 48 & 200 & 6 & 6 \\
\hline 3 & 58 & 200 & 4 & 8 & 33 & 44 & 100 & 5 & 6 \\
\hline 4 & 49 & 100 & 4 & 7 & 34 & 56 & 100 & 5 & 8 \\
\hline 5 & 19 & 100 & 4 & 7 & 35 & 55 & 100 & 4 & 8 \\
\hline 6 & 30 & 200 & 6 & 8 & 36 & 54 & 200 & 6 & 7 \\
\hline 7 & 45 & 100 & 6 & 6 & 37 & 47 & 200 & 5 & 6 \\
\hline 8 & 13 & 100 & 4 & 6 & 38 & 27 & 100 & 6 & 8 \\
\hline 9 & 26 & 100 & 5 & 8 & 39 & 18 & 200 & 6 & 6 \\
\hline 10 & 40 & 200 & 4 & 5 & 40 & 60 & 200 & 6 & 8 \\
\hline 11 & 42 & 200 & 6 & 5 & 41 & 31 & 100 & 4 & 4 \\
\hline 12 & 34 & 200 & 4 & 4 & 42 & 46 & 200 & 4 & 6 \\
\hline 13 & 52 & 200 & 4 & 7 & 43 & 29 & 200 & 5 & 8 \\
\hline 14 & 21 & 100 & 6 & 7 & 44 & 50 & 100 & 5 & 7 \\
\hline 15 & 3 & 100 & 6 & 4 & 45 & 43 & 100 & 4 & 6 \\
\hline 16 & 7 & 100 & 4 & 5 & 46 & 9 & 100 & 6 & 5 \\
\hline 17 & 25 & 100 & 4 & 8 & 47 & 53 & 200 & 5 & 7 \\
\hline 18 & 37 & 100 & 4 & 5 & 48 & 2 & 100 & 5 & 4 \\
\hline 19 & 23 & 200 & 5 & 7 & 49 & 32 & 100 & 5 & 4 \\
\hline 20 & 6 & 200 & 6 & 4 & 50 & 38 & 100 & 5 & 5 \\
\hline 21 & 17 & 200 & 5 & 6 & 51 & 51 & 100 & 6 & 7 \\
\hline 22 & 11 & 200 & 5 & 5 & 52 & 57 & 100 & 6 & 8 \\
\hline 23 & 36 & 200 & 6 & 4 & 53 & 22 & 200 & 4 & 7 \\
\hline 24 & 12 & 200 & 6 & 5 & 54 & 41 & 200 & 5 & 5 \\
\hline 25 & 24 & 200 & 6 & 7 & 55 & 39 & 100 & 6 & 5 \\
\hline 26 & 8 & 100 & 5 & 5 & 56 & 14 & 100 & 5 & 6 \\
\hline 27 & 1 & 100 & 4 & 4 & 57 & 16 & 200 & 4 & 6 \\
\hline 28 & 15 & 100 & 6 & 6 & 58 & 5 & 200 & 5 & 4 \\
\hline 29 & 33 & 100 & 6 & 4 & 59 & 10 & 200 & 4 & 5 \\
\hline 30 & 35 & 200 & 5 & 4 & 60 & 4 & 200 & 4 & 4 \\
\hline
\end{tabular}


Table 3 - The mesh sensitivity test.

\begin{tabular}{|c|c|c|c|c|}
\hline Analysis No. & $\begin{array}{c}\text { Element size in fine } \\
\text { areas (HAZ) OR } \\
\text { Reference Element } \\
\text { size (mm) }\end{array}$ & $\begin{array}{c}\text { Element size near } \\
\text { the HAZ (mm) }\end{array}$ & $\begin{array}{c}\text { Element size far } \\
\text { from the HAZ } \\
\text { (mm) }\end{array}$ & Solving time \\
\hline 1 & 0.3 & 0.6 & 1.2 & $\mathbf{6 0}$ \\
\hline 2 & 0.2 & 0.4 & 0.8 & $\mathbf{1 2 0}$ \\
\hline 3 & 0.1 & 0.2 & 0.4 & $\mathbf{3 9 0}$ \\
\hline 4 & 0.05 & 0.1 & 0.2 & $\mathbf{1 5 6 0}$ \\
\hline
\end{tabular}


Table 4. The boundary conditions.

\begin{tabular}{|c|c|c|}
\hline Item & Formula & Boundary condition \\
\hline Cooling by air & $-k \frac{\partial T}{\partial r}=\alpha_{\infty}\left(T-T_{\infty}\right)$ & Free surfaces of sheet and electrode \\
$-k \frac{\partial T}{\partial z}=\alpha_{\infty}\left(T-T_{\infty}\right)$ & \\
\hline Cooling by water & $-k \frac{\partial T}{\partial r}=\alpha_{w}\left(T-T_{w}\right)$ & Electrode inner surface \\
& $-k \frac{\partial T}{\partial z}=\alpha_{w}\left(T-T_{w}\right)$ & \\
\hline Symmetry condition & $\frac{\partial T}{\partial r}=0$ & $\boldsymbol{x}=\mathbf{0}$ \\
\hline Applying Current & $\frac{\partial \phi}{\partial r}=0$ & Upper electrode \\
\hline
\end{tabular}


Table 5. The boundary conditions.

\begin{tabular}{|c|c|c|}
\hline Item & Formula & Boundary condition \\
\hline Displacement & $U_{z}=0$ & Lower electrode \\
\hline Electrode Pressure & $\sigma_{z}=P$ & Upper electrode \\
\hline Symmetry & $U_{r}=0$ & $\boldsymbol{x}=\mathbf{0}$ \\
\hline
\end{tabular}

Table 6. The physical and mechanical properties of the sheet

\begin{tabular}{|c|c|c|c|c|c|}
\hline Temperature $\left({ }^{\circ} \mathrm{C}\right)$ & $\begin{array}{c}\text { Specific heat } \\
\left(\mathrm{J} / \mathrm{Kg}^{\circ} \mathrm{C}\right)\end{array}$ & $\begin{array}{l}\text { Conductivity } \\
\left(\mathrm{J} / \mathrm{m}^{\circ} \mathrm{Cs}\right)\end{array}$ & $\begin{array}{c}\text { Thermal } \\
\text { expansion } \\
\text { coefficient } \\
\left({ }^{\circ} \mathrm{C}^{-1} \times 10^{-5}\right)\end{array}$ & $\begin{array}{c}\text { Electrical } \\
\text { resistivity } \\
(\mu \Omega \mathrm{m})\end{array}$ & $\begin{array}{c}\text { Young's } \\
\text { modulus } \\
\text { (GPa) }\end{array}$ \\
\hline 21 & 443.8 & 64.75 & 1.1 & 0.142 & 206 \\
\hline 93 & 452.2 & 63.25 & 1.15 & 0.186 & 196 \\
\hline 204 & 510.8 & 55.33 & 1.22 & .266 & 194 \\
\hline 316 & 561 & 49.94 & 1.3 & .376 & 176 \\
\hline 427 & 611.3 & 44.86 & 1.35 & .495 & 169 \\
\hline 538 & 661.5 & 39.77 & 1.4 & .647 & 117 \\
\hline 649 & 762 & 34.91 & 1.46 & .817 & 55 \\
\hline 732 & 1004 & & & & \\
\hline 760 & 1189 & 30.5 & 1.4 & 1.01 & \\
\hline 774 & 1189 & & & & \\
\hline 871 & & 28.41 & 1.35 & 1.12 & \\
\hline 982 & & 27.66 & & 1.16 & \\
\hline 1093 & & 28.56 & & 1.18 & \\
\hline 1204 & & & & 1.21 & \\
\hline
\end{tabular}


Table 7. The physical and mechanical properties of the electrode

\begin{tabular}{|c|c|c|c|c|c|}
\hline Temperature $\left({ }^{\circ} \mathrm{C}\right)$ & $\begin{array}{c}\text { Specific heat } \\
\left(\mathrm{J} / \mathrm{Kg}^{\circ} \mathrm{C}\right)\end{array}$ & $\begin{array}{c}\text { Conductivity } \\
\left(\mathrm{J} / \mathrm{m}^{\circ} \mathrm{Cs}\right)\end{array}$ & $\begin{array}{c}\text { Thermal } \\
\text { expansion } \\
\text { coefficient } \\
\left({ }^{\circ} \mathrm{C}^{-1} \times 10^{-5}\right)\end{array}$ & $\begin{array}{c}\text { Electrical } \\
\text { resistivity } \\
(\mu \Omega \mathrm{m})\end{array}$ & $\begin{array}{c}\text { Young's } \\
\text { modulus } \\
\text { (GPa) }\end{array}$ \\
\hline 21 & 397 & 390.3 & 1.656 & 0.0264 & 124 \\
\hline 93 & 402 & 380.6 & 1.674 & 0.0300 & 105 \\
\hline 204 & 419 & 370.1 & 1.710 & 0.0400 & 93 \\
\hline 316 & 431 & 355.1 & 1.746 & 0.0505 & 82 \\
\hline 427 & 440 & 345.4 & 1.782 & 0.0619 & 55 \\
\hline 538 & 452 & 334.9 & 1.836 & 0.0699 & 38 \\
\hline 649 & 465 & 320.0 & 1.854 & 0.0800 & 25 \\
\hline 760 & 477 & 315.5 & 1.890 & 0.0898 & 16 \\
\hline 871 & & 310.3 & 1.926 & 0.0948 & 14 \\
\hline 982 & & 305.0 & & 0.0998 & 7 \\
\hline 1093 & & 300.1 & & & \\
\hline 1204 & 502 & & & & \\
\hline
\end{tabular}




\section{Figures}
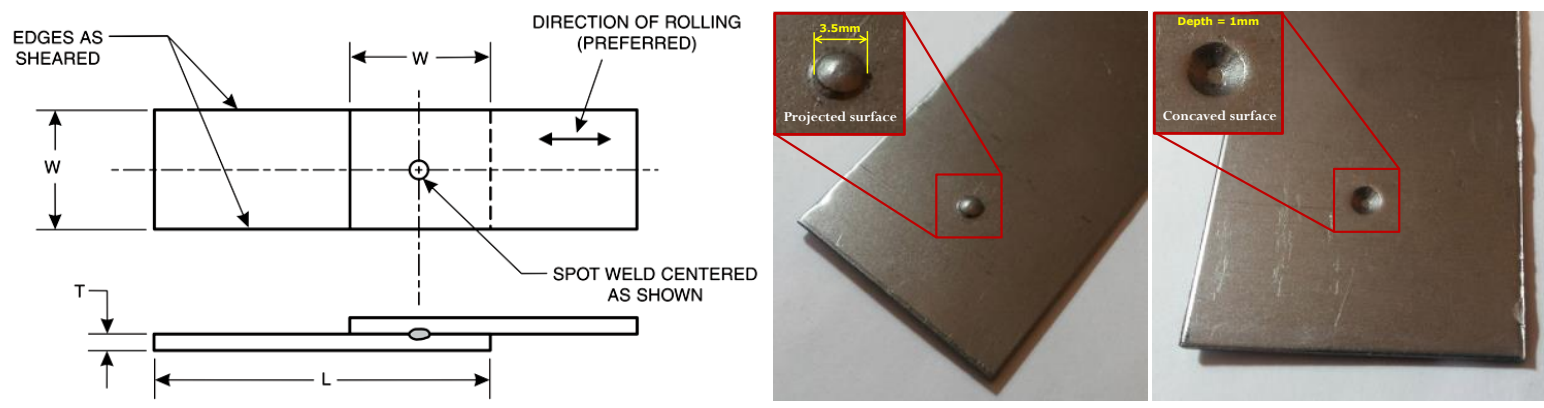

Fig. 1. Sample preparation and shape size. 

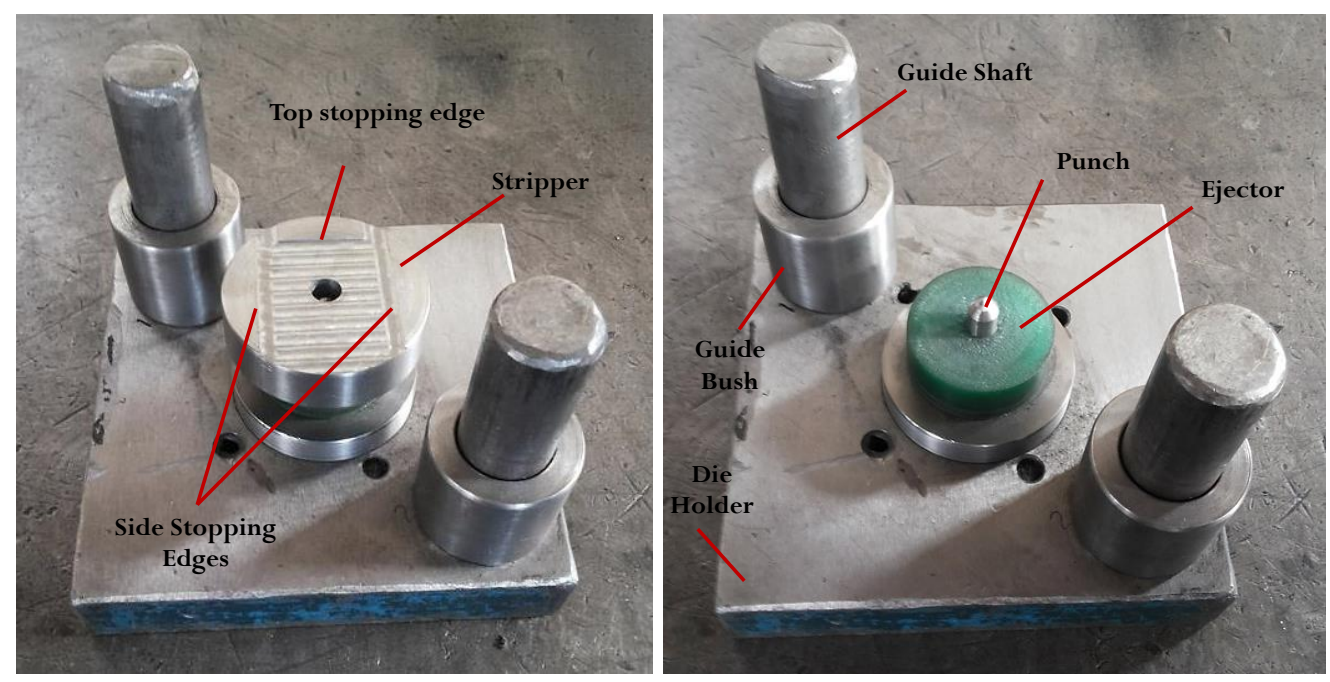

Fig. 2. Forming die to form the projected neck.
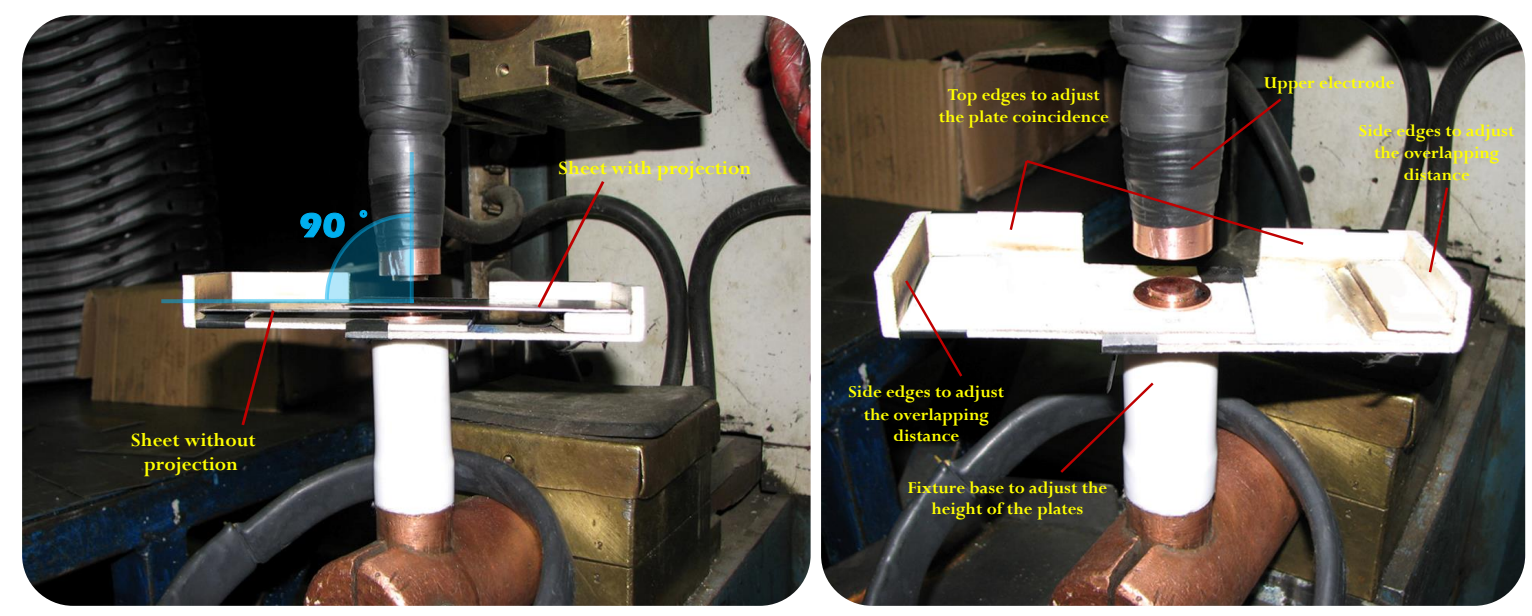

Fig. 3. Welding fixture and adjustment of the plates during welding. 


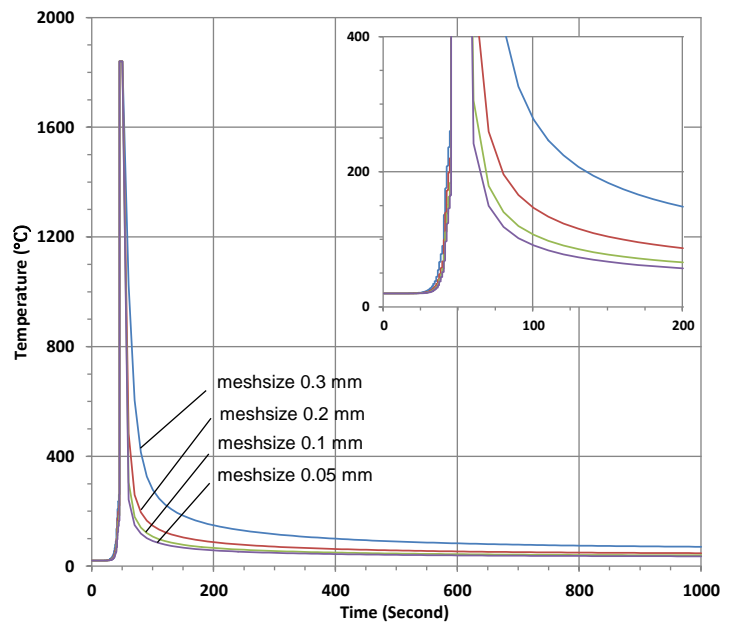

Fig. 4. The change of temperature versus time in different mesh size. 

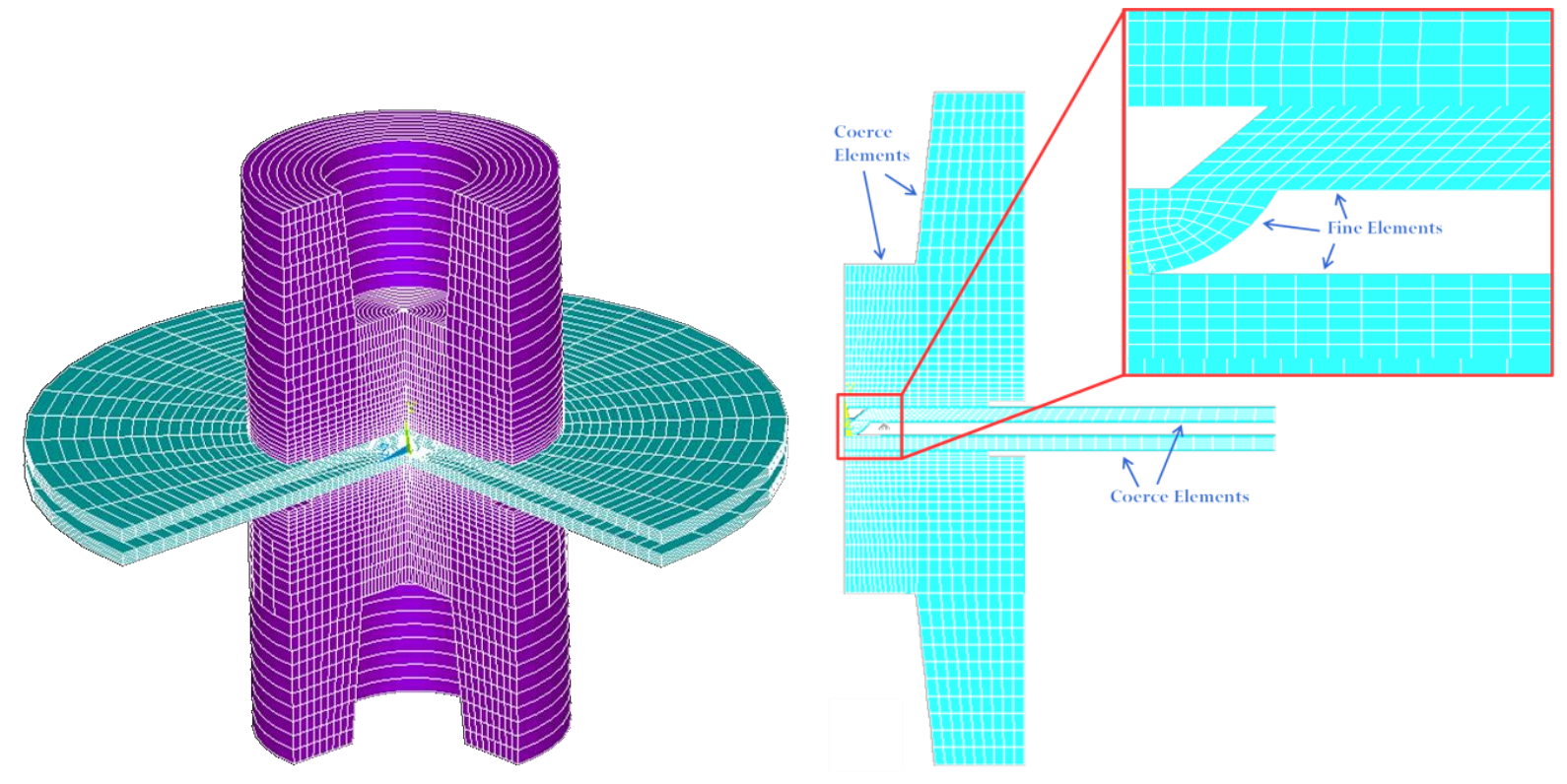

Fig. 5. Numerical model in ANSYS.

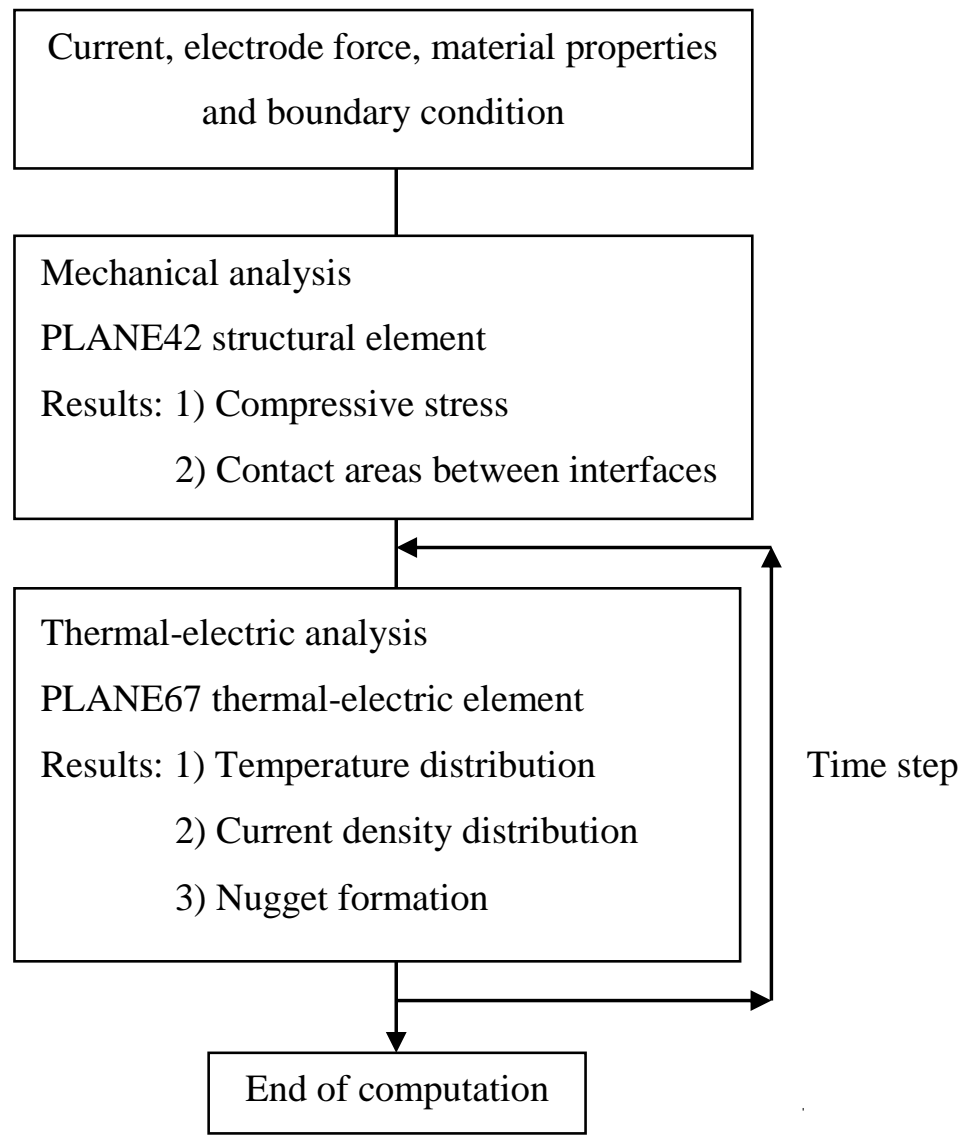

Fig. 6. The simulation procedure and steps. 

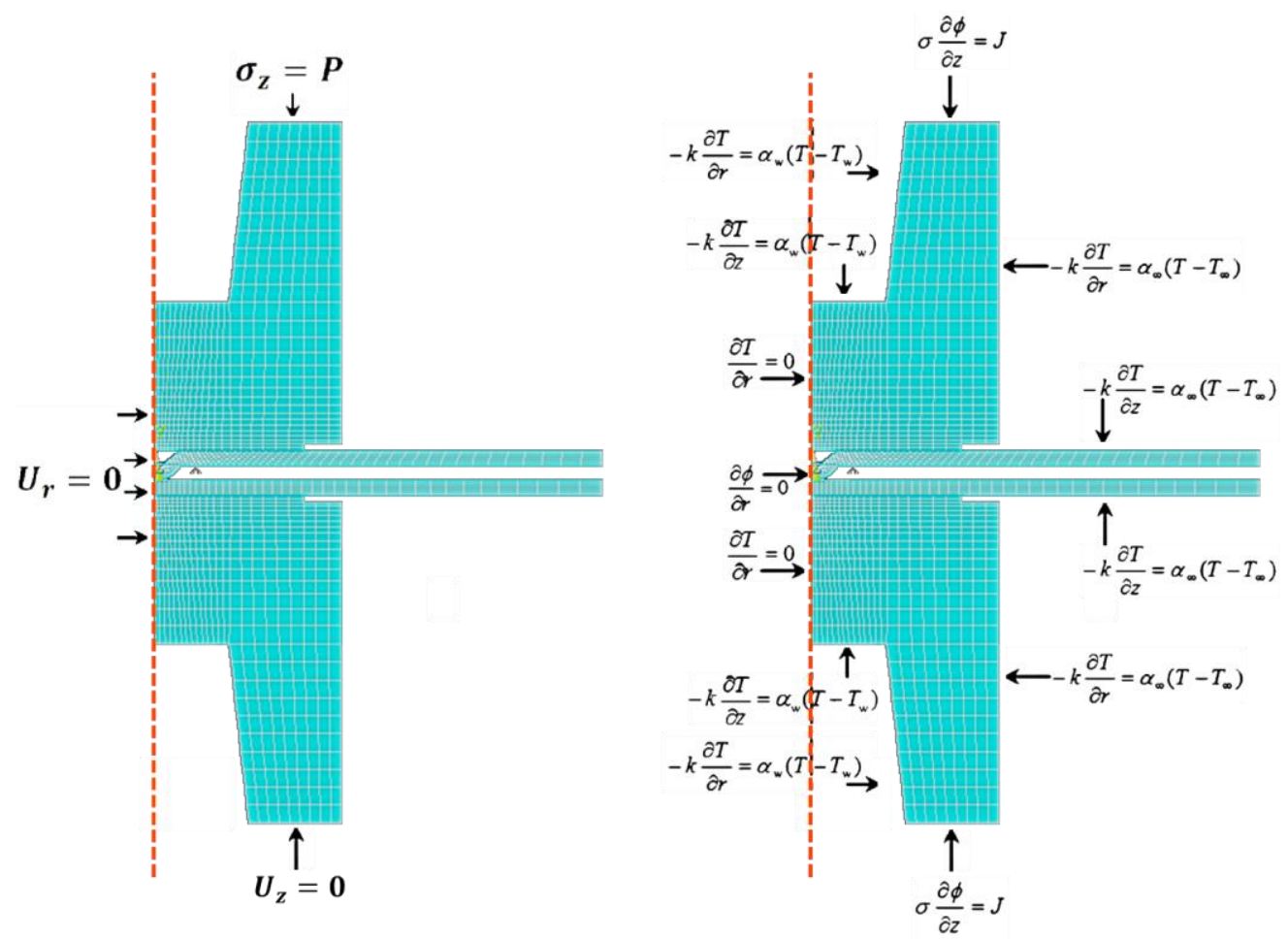

Fig. 7. The boundary conditions. 

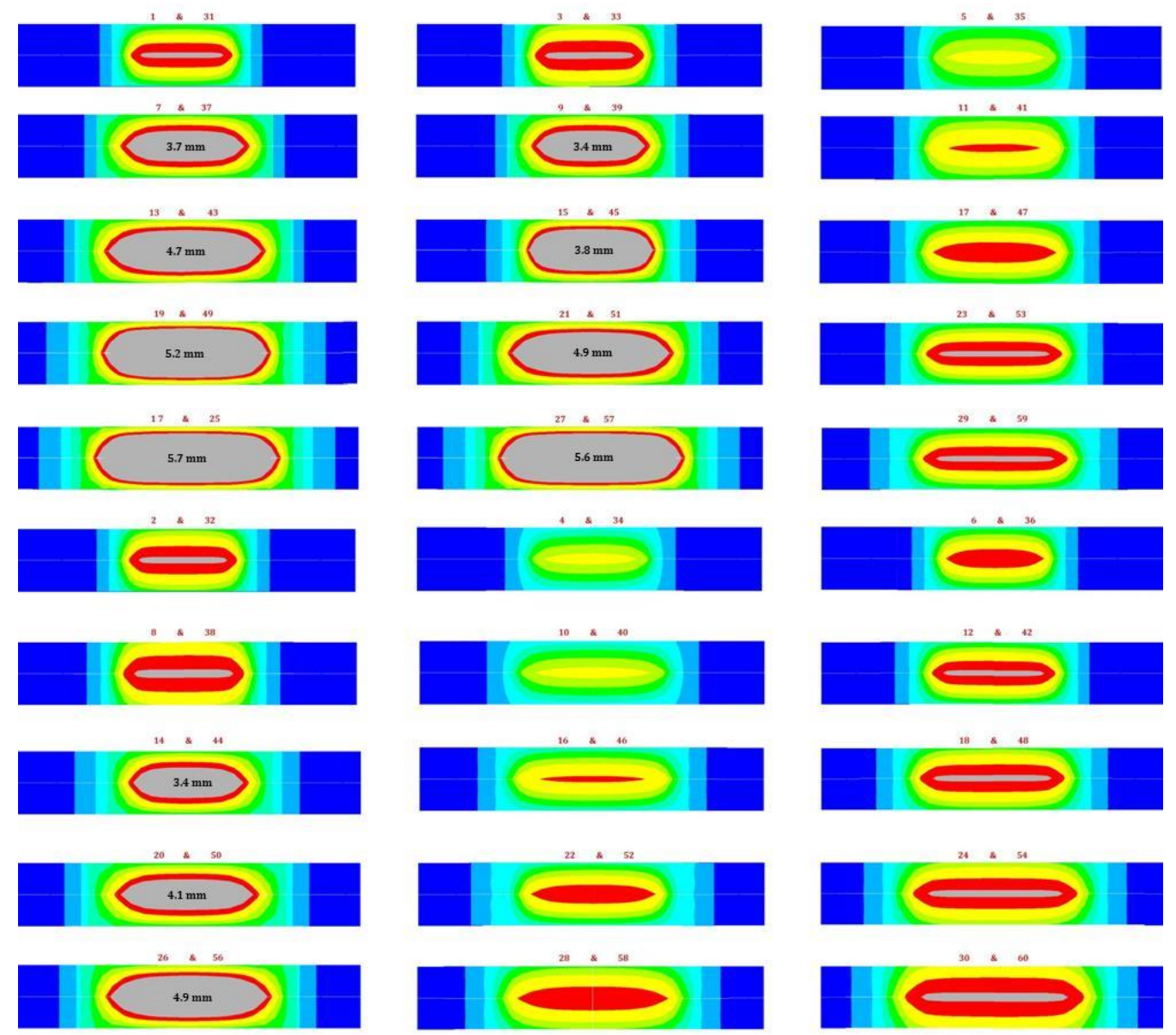

Fig. 8. The simulation results as temperature gradients. 


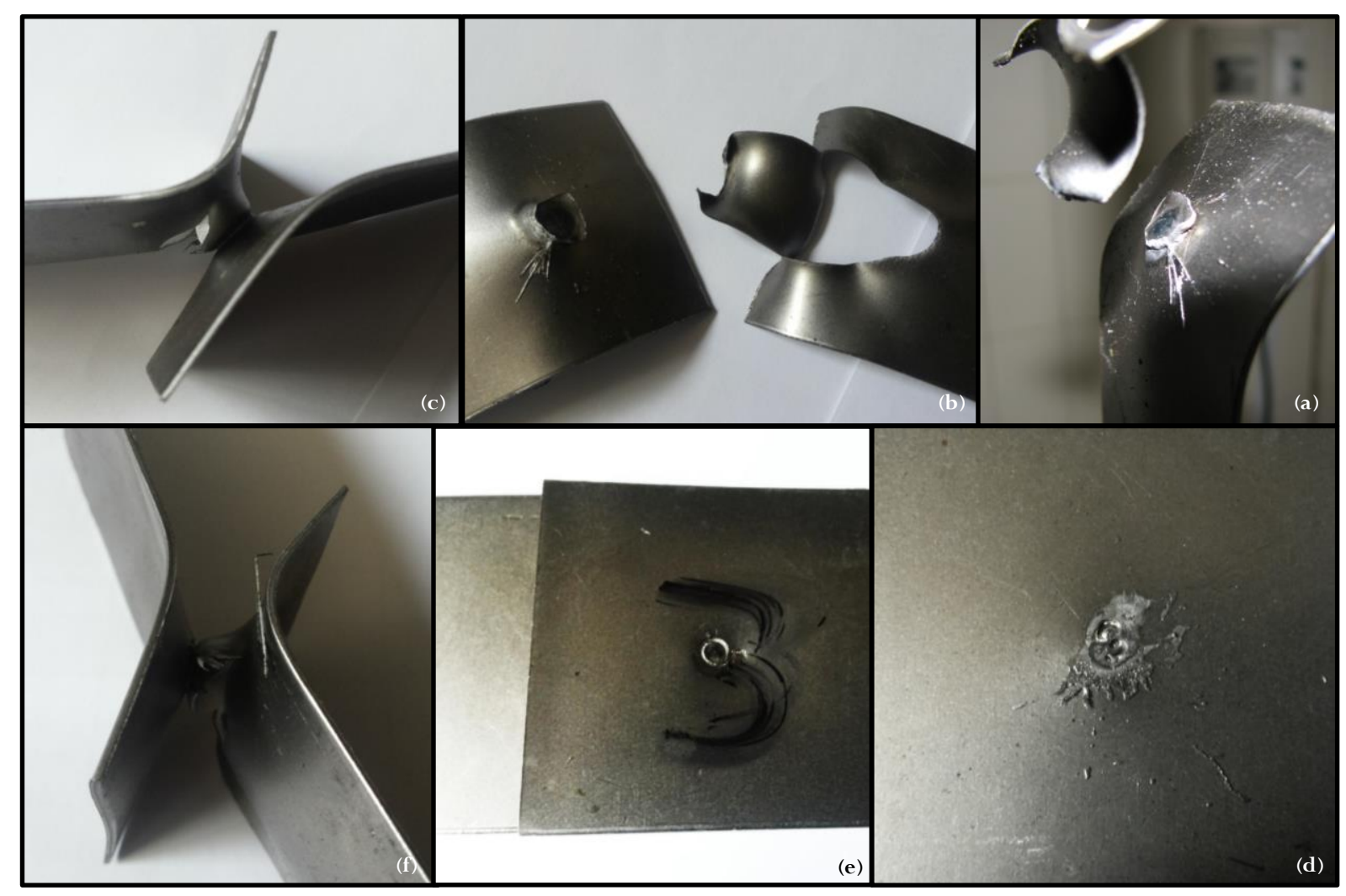

Fig. 9. The peeling test and final results. 


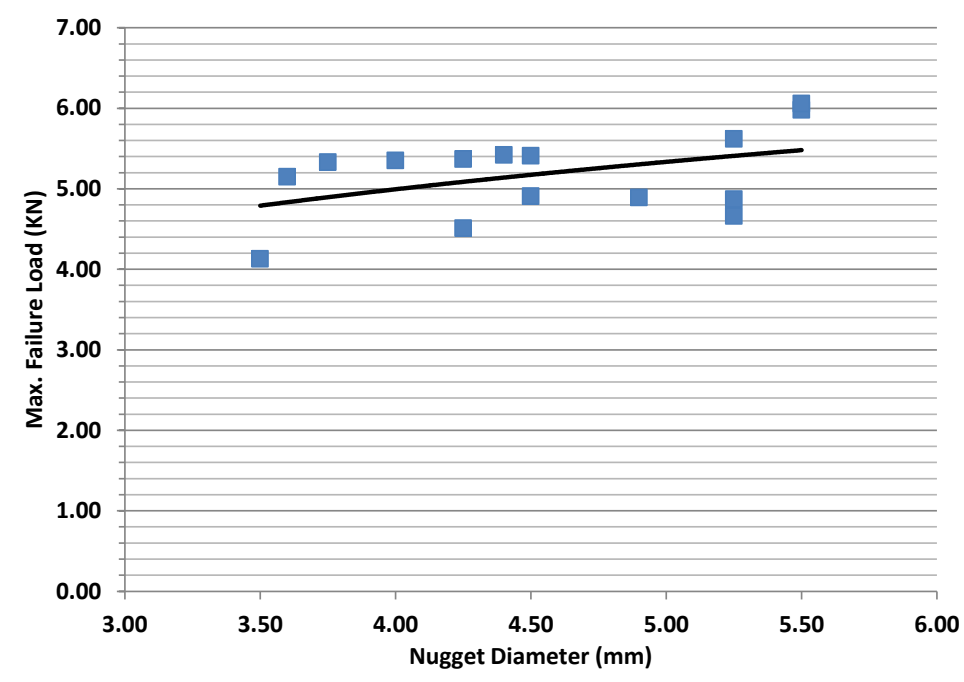

Fig. 10. Maximum failure load versus nugget diameter. 


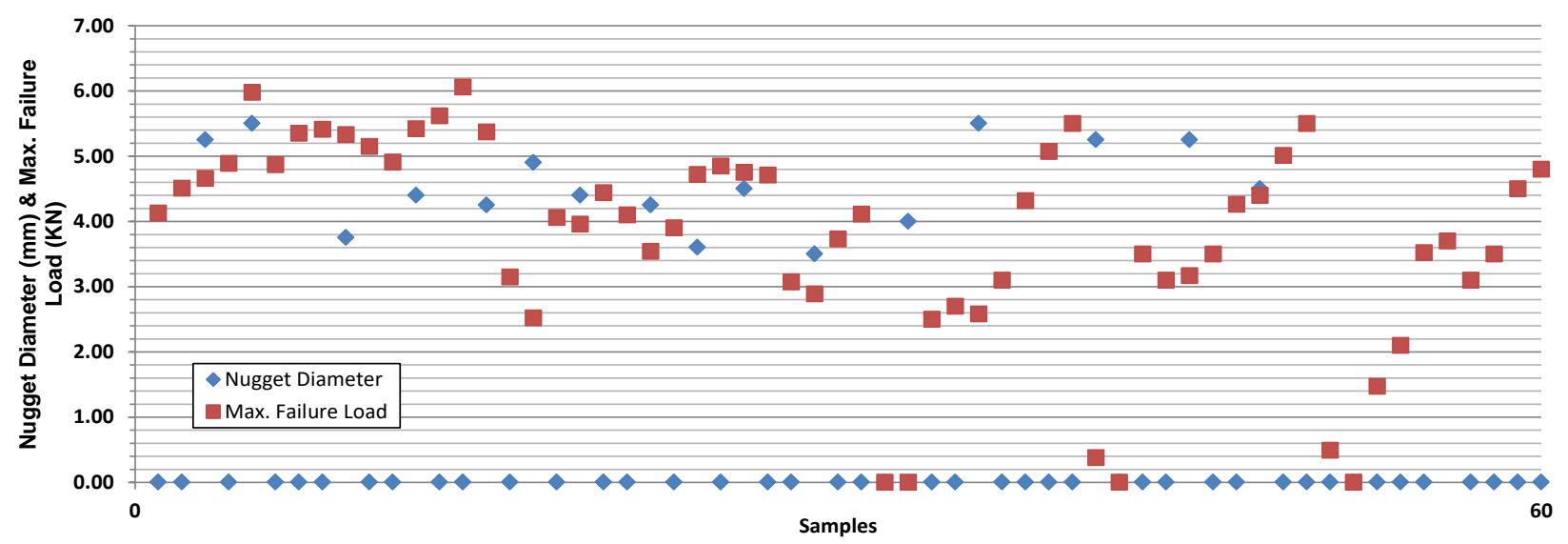

Fig. 11. The dispersion of nugget diameter and maximum failure load in all samples. 


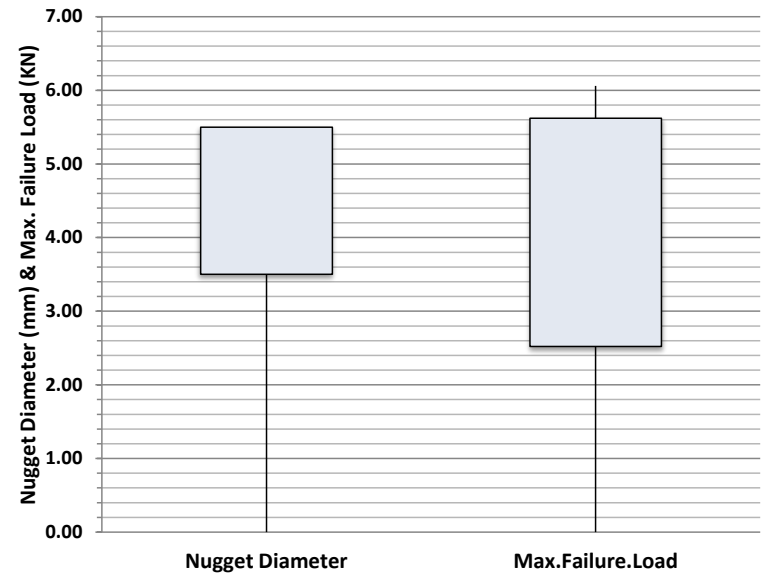

Fig. 12. The dispersion of nugget diameter and maximum failure load in all samples. 

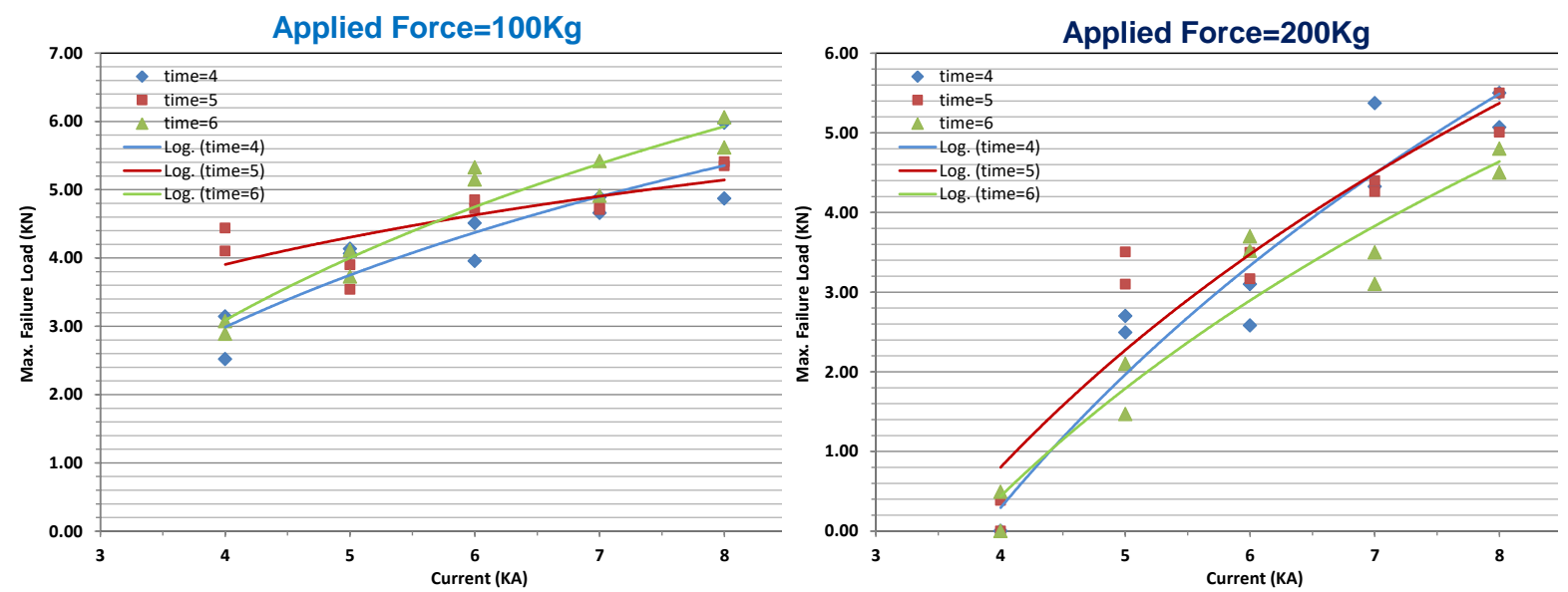

Fig. 13. The influence of welding current on maximum failure load. 

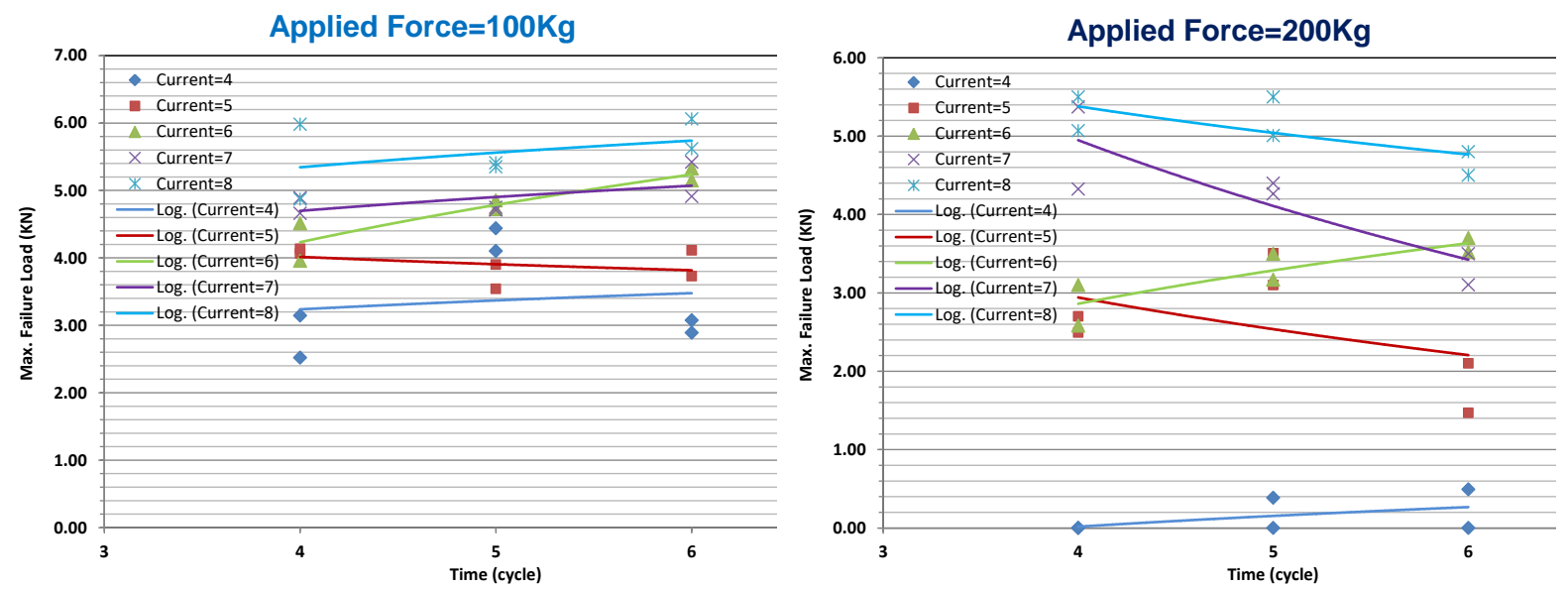

Fig. 14. The influence of weld time on maximum failure load. 


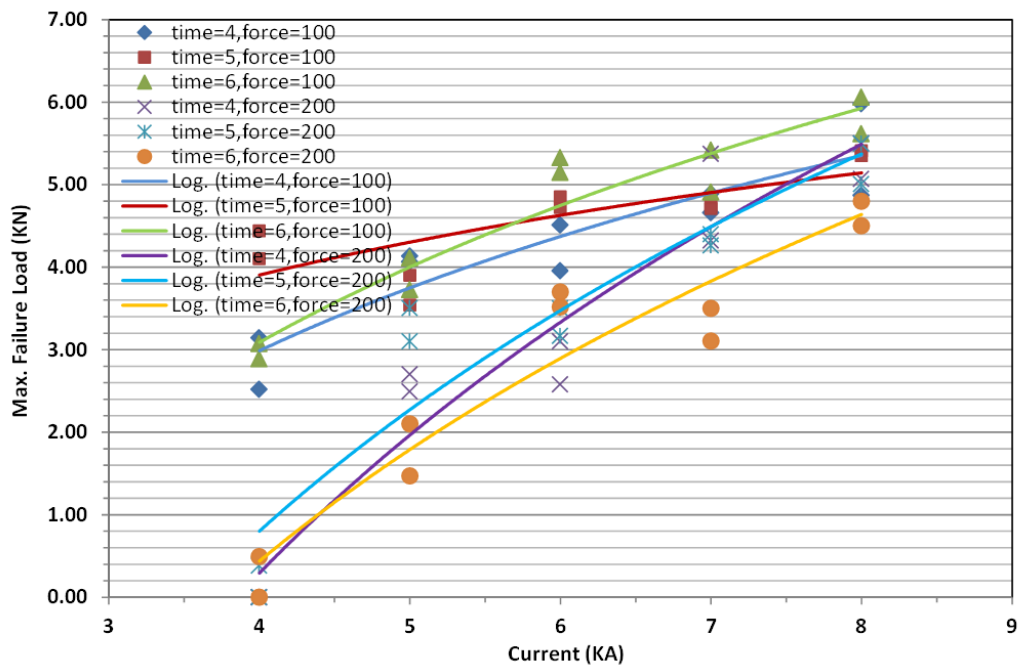

Fig. 15. The influence of welding force on maximum failure load. 


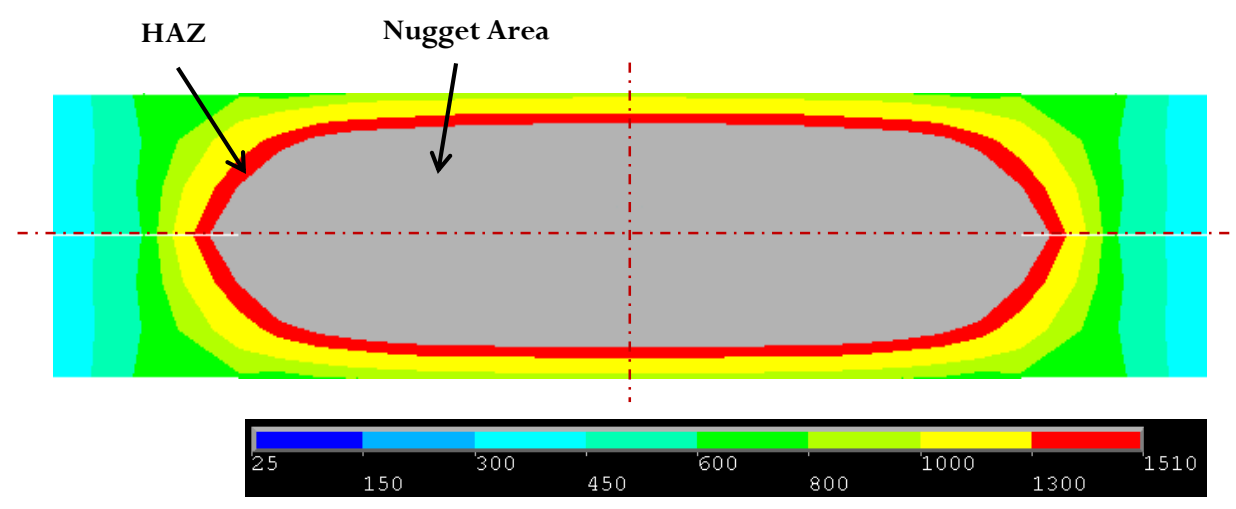

Fig. 16. The influence of welding force on maximum failure load. 

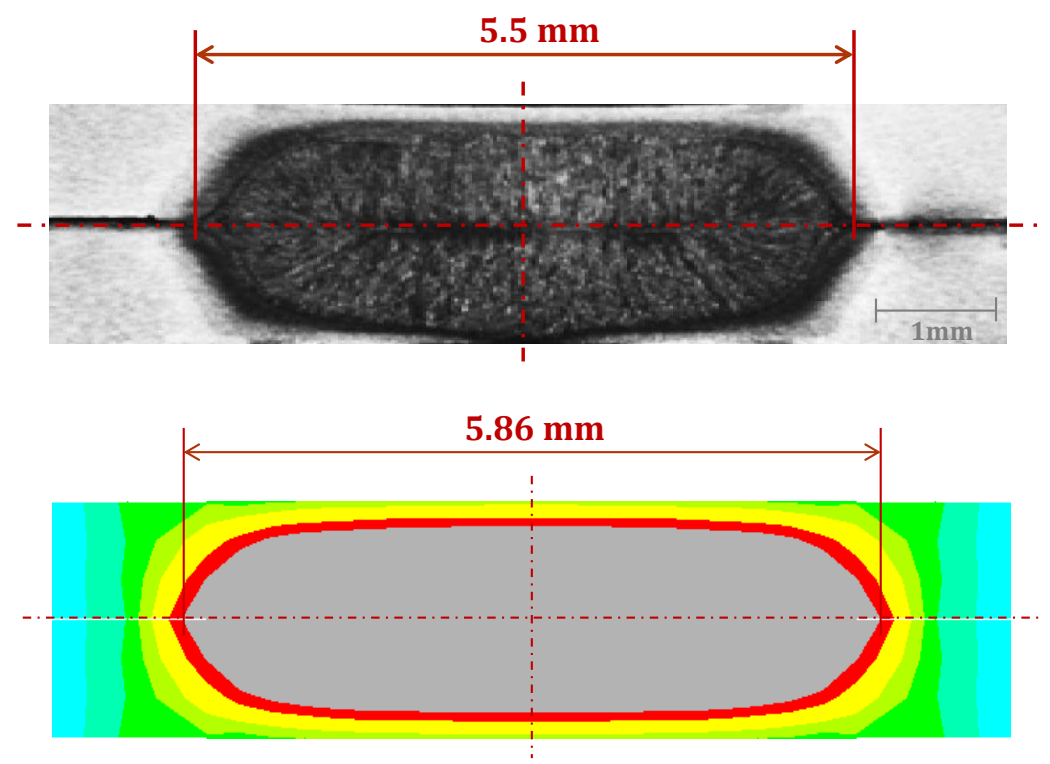

Fig. 17. The influence of welding force on maximum failure load. 


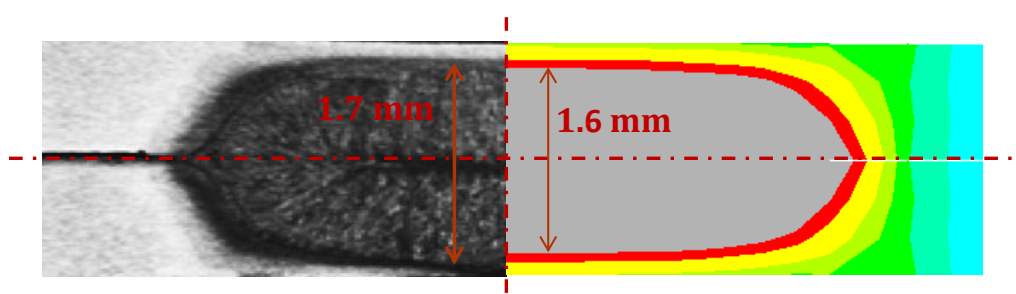

Fig. 18. The influence of welding force on maximum failure load. 

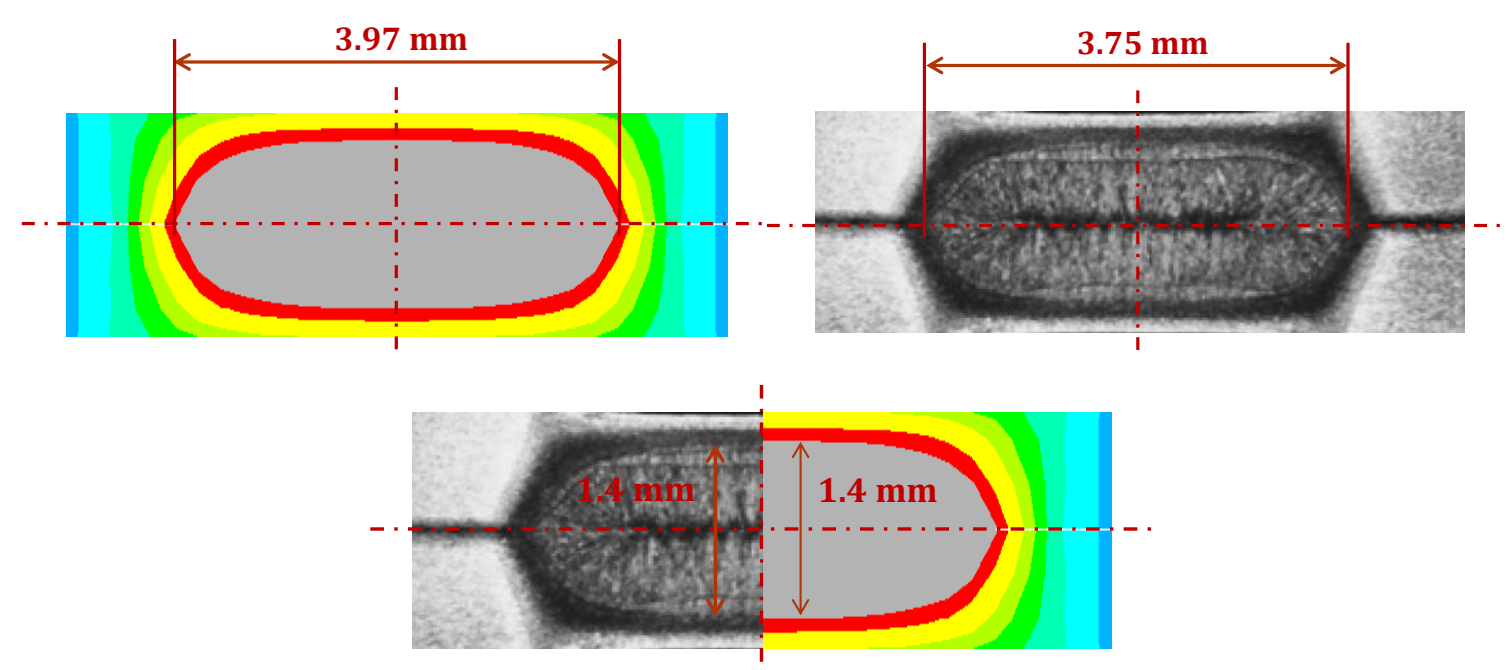

Fig. 19. The influence of welding force on maximum failure load. 